\title{
Spatial Downscaling of Tropical Rainfall Measuring Mission (TRMM) Annual and Monthly Precipitation Data over the Middle and Lower Reaches of the Yangtze River Basin, China
}

\author{
Shaodan Chen, Liping Zhang *, Dunxian She and Jie Chen
}

State Key Laboratory of Water Resources and Hydropower Engineering Science, Wuhan University, No. 8 Donghu South Road, Wuhan 430072, China; chensd2014@163.com (S.C.); shedunxian@whu.edu.cn (D.S.); jiechen@whu.edu.cn (J.C.)

* Correspondence: zhanglp@whu.edu.cn

Received: 23 January 2019; Accepted: 13 March 2019; Published: 19 March 2019

\begin{abstract}
Precipitation plays an important role in the global water cycle, in addition to material and energy exchange processes. Therefore, obtaining precipitation data with a high spatial resolution is of great significance. We used a geographically weighted regression (GWR)-based downscaling model to downscale Tropical Rainfall Measuring Mission (TRMM) 3B43 precipitation data over the middle and lower reaches of the Yangtze River Basin (MLRYRB) from a resolution of $0.25^{\circ}$ to $1 \mathrm{~km}$ on an annual scale, and the downscaled results were calibrated using the geographical differential analysis (GDA) method. At present, either the normalized difference vegetation index (NDVI) or a digital elevation model (DEM) is selected as the environmental variable in the downscaling models. However, studies have shown that the relationship between the NDVI and precipitation gradually weakens when precipitation exceeds a certain threshold. In contrast, the enhanced vegetation index (EVI) overcomes the saturation shortcomings of the NDVI. Therefore, this study investigated the performances of EVI-derived and NDVI-derived downscaling models in downscaling TRMM precipitation data. The results showed that the NDVI performed better than the EVI in the annual downscaling model, possibly because this study used the annual average NDVI, which may have neutralized detrimental saturation effects. Moreover, the accuracy of the downscaling model could be effectively improved after correcting for residuals and calibrating the model with the GDA method. Subsequently, the downscaled rainfall was closer to the actual weather station rainfall observations. Furthermore, the downscaled results were decomposed into fractions to obtain monthly precipitation data, showing that the proposed method by utilizing the GDA method could improve not only the spatial resolution of remote sensing precipitation data, but also the accuracy of data.
\end{abstract}

Keywords: precipitation; Tropical Rainfall Measuring Mission (TRMM); downscaling; (geographically weighted regression) GWR; normalized difference vegetation index (NDVI); enhanced vegetation index (EVI)

\section{Introduction}

Precipitation plays an important role in the exchange of material and energy in the global water cycle and affects soil moisture, vegetation growth, and surface runoff [1-3]. Consequently, precipitation constitutes the key parameter of various hydrological models, and the quality of precipitation data directly affects the results of model simulations [4]. Hence, the quality of these data is of great significance for studying global climate change, assessing surface runoff conditions, and providing 
biomass estimations. Obtaining precipitation data with a high spatial resolution is therefore necessary for conducting research on ecology, the environment, and hydrology on a global scale.

Generally, rainfall observation stations have a relatively higher observation accuracy at the site scale, but it is difficult to completely reproduce the spatiotemporal distribution of precipitation due to sparse or uneven spatial distribution of weather stations. In recent years, a series of satellite remote sensing precipitation products [5-7], such as the Global Satellite Mapping of Precipitation (GSMaP) project at $0.1^{\circ} \times 0.1^{\circ}$ resolution [8], the Global Precipitation Climatology Project (GPCP) at $2.5^{\circ} \times 2.5^{\circ}$ resolution [9,10], the Tropical Rainfall Measuring Mission (TRMM) [11-13], and the Global Precipitation Measurement (GPM) mission with $10 \mathrm{~km} \times 10 \mathrm{~km}$ resolution [14], have provided new global and regional precipitation observations. Among them, TRMM data products offer a spatial resolution of $0.25^{\circ} \times 0.25^{\circ}$ [11]. However, when applied to research on hydrology, ecology, climates, etc., at the regional scale, various models require higher-resolution precipitation data as input parameters to obtain more accurate simulation results, and a spatial resolution of $0.25^{\circ} \times 0.25^{\circ}$ cannot meet these demands [15]. Therefore, it is necessary to develop a downscaling algorithm for satellite precipitation products to obtain accurate data with a high spatial resolution.

Although the dynamic downscaling method has a clear physical meaning and is applied to any place without being affected by observation data, it is computationally intensive and susceptible to mode system errors. The main principle of the statistical spatial downscaling method is based on the relationships between precipitation and various land surface environmental variables. The corresponding statistical model, which is established at a coarse resolution, is applied to high-resolution variables of the land surface environment to downscale the precipitation data. Since the launch of the TRMM, research on the downscaling of TRMM precipitation data has become increasingly popular [16-19]. At present, either the normalized difference vegetation index (NDVI) or a digital elevation model (DEM) is selected as the environmental variable for downscaling models $[14,20,21]$. For example, Immerzeel et al. [17] developed an exponential relationship between precipitation and the NDVI to downscale TRMM data over the Iberian Peninsula on an annual scale. Considering the effects of topography on precipitation, Jia et al. [16] used the NDVI and a DEM as surface explanatory variables and established a multiple linear regression (MLR) model to downscale TRMM data from $0.25^{\circ}$ (approximately $27 \mathrm{~km}$ ) to $1 \mathrm{~km}$. Subsequent studies have shown that MLR-based downscaling models can achieve fine-resolution precipitation data [16,22].

The methods used in the previous mentioned studies [1,14] assume that the relationships between precipitation and surface environmental variables (such as the NDVI or DEM) are spatially constant, however, some scholars believe that the relationships between precipitation and environmental variables are not stable and should vary in space $[23,24]$. Accordingly, based on a local regression model, Brunsdon et al. [25] proposed a geographically weighted regression (GWR) model to explore this spatial nonstationarity $[26,27]$. GWR introduces primarily geographical location information into a regression model based on the similarity between the dependent variable and the explanatory variable in a particular geographical location. A GWR-based downscaling algorithm performs better at downscaling precipitation data than an MLR-based downscaling algorithm. However, the GWR-based downscaling algorithm suffers from certain limitations in applications involving the downscaling of TRMM data. Nevertheless, studies have shown that the relationship between the NDVI and precipitation gradually weakens when the precipitation exceeds a certain threshold. Alternatively, the enhanced vegetation index (EVI) overcomes the saturation shortcomings of the NDVI and exhibits a better response to precipitation $[28,29]$. At present, there have been relatively few studies on the use of the EVI in the downscaling model. Zhang et al. [30] used the EVI instead of the NDVI to estimate particulate matter less than $2.5 \mu \mathrm{m}\left(\mathrm{PM}_{2.5}\right)$ in the GWR model. The results showed that the EVI-based model was more effective than the previous GWR model. Moreover, in the downscaling model of precipitation, Shi et al. [31] introduced the EVI into the random forest model to downscale precipitation over the Tibetan Plateau. In this study, we attempted to investigate the performances of both EVI-derived and NDVI-derived downscaling models at downscaling TRMM precipitation 
data. In addition, the NDVI response to precipitation has a time lag on a monthly scale. Therefore, downscaling models are used to downscale monthly precipitation data, which is likely to produce large errors.

The purpose of this study was to use the GWR model to downscale TRMM precipitation products in the study area to obtain higher-resolution precipitation data. The specific objectives were as follows: (1) To use the GWR-based downscaling model to downscale TRMM 3B43 precipitation data from $0.25^{\circ}$ to $1 \mathrm{~km}$ on an annual scale in the middle and lower reaches of the Yangtze River Basin (MLRYRB); (2) to investigate the efficiencies of the NDVI-based and EVI-based GWR models; and (3) to obtain monthly precipitation data based on the calibration of the annual downscaling results and evaluate the accuracy of those data.

\section{Data and Methods}

\subsection{Study Area}

The Yangtze River Basin is the third-largest river basin in the world, with a total drainage area of approximately 1.8 million $\mathrm{km}^{2}$, accounting for $18.8 \%$ of China's land area [32]. The annual precipitation in the MLRYRB, which was chosen as the study area (as shown in Figure 1), is 1000-1400 mm, and the distribution of precipitation decreases from southeast to northwest. Generally, precipitation reaches a maximum in summer, followed by spring, autumn, and winter.

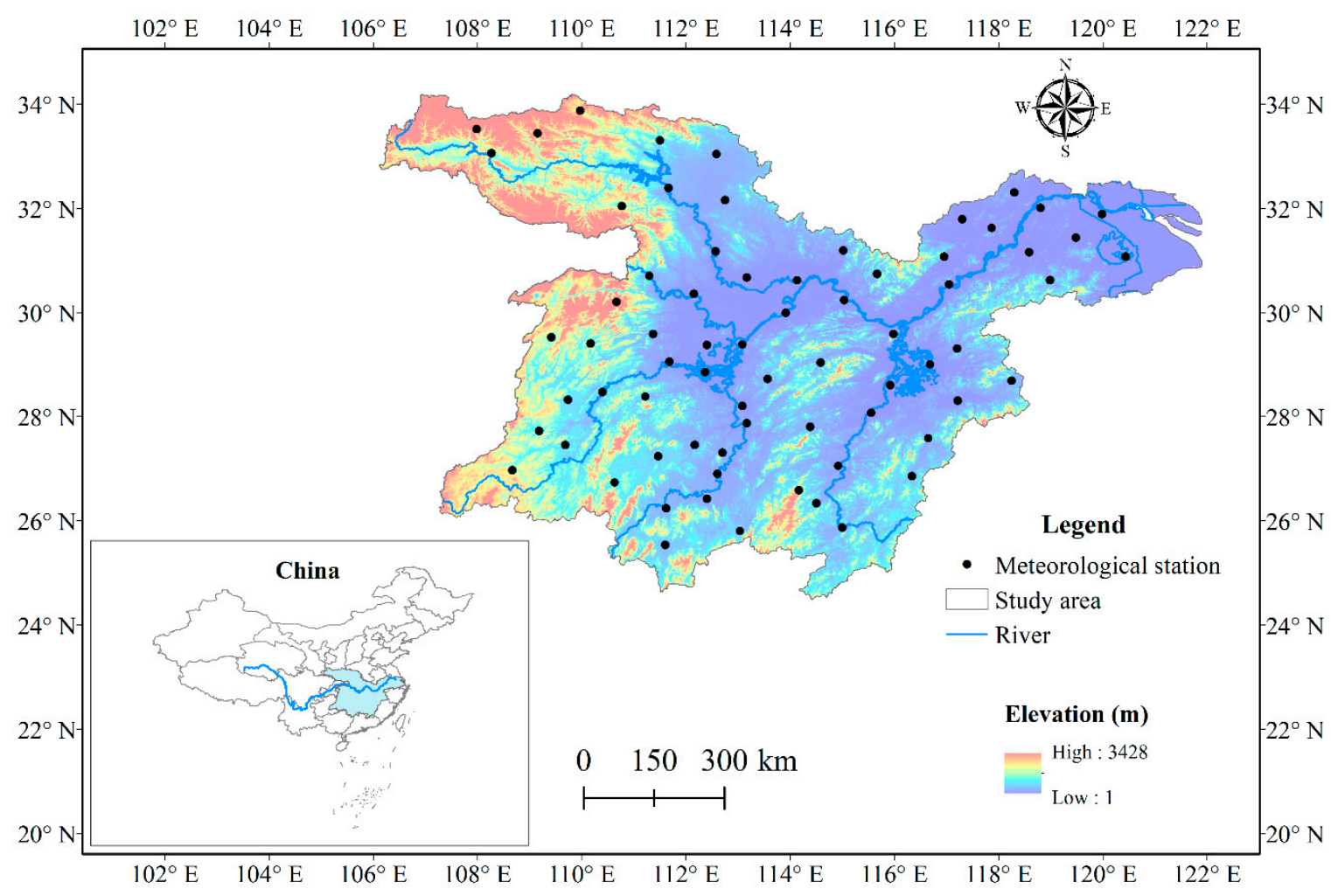

Figure 1. The locations of the meteorological stations and the digital elevation model (DEM) over the middle and lower reaches of the Yangtze River Basin (MLRYRB).

\subsection{Data}

The TRMM satellite, sponsored by the National Aeronautics and Space Administration (NASA) and the Japan Aerospace Exploration Agency (JAXA), was successfully launched in November 1997. This study used the TRMM 3B43 monthly product, with a spatial resolution of $0.25^{\circ} \times 0.25^{\circ}$ over a latitude range from $50^{\circ} \mathrm{S}$ to $50^{\circ} \mathrm{N}$ [33,34]. The TRMM 3B43 product incorporates satellite rainfall estimates with gauge data into gridded estimates. In addition, the Moderate Resolution Imaging 
Spectroradiometer (MODIS) instruments on board the Terra and Aqua satellites are designed to observe the earth's surface, and the MODIS products provide data beginning in 2000 [35-37]. Therefore, we downscaled the TRMM precipitation products during the period 2000-2016. Furthermore, for comparative analysis, we also selected the GPM-3IMERGM precipitation product (available at https: / / pmm.nasa.gov/data-access/downloads/gpm), which provides data beginning in March 2014 with a spatial resolution of $10 \mathrm{~km} \times 10 \mathrm{~km}$ [38].

The NDVI and EVI products, which provide monthly data at a $1 \mathrm{~km} \times 1 \mathrm{~km}$ spatial resolution as a gridded level-3 product in the sinusoidal projection, were obtained from the Terra MODIS Vegetation Indices Version 6 data product (MOD13A3) [39]. The annual NDVI and EVI were obtained by averaging the monthly NDVI and EVI, respectively. Additionally, the Shuttle Radar Topography Mission (SRTM) DEM product was provided by the International Scientific \& Technical Data Mirror Site, Computer Network Information Center, Chinese Academy of Science, with a spatial resolution of 90 m (http:/ / www.gscloud.cn).

The monthly precipitation data recorded at 70 meteorological stations from 2000 to 2016 used in this study were provided from the China Meteorological Data Sharing Service System (available at http:/ / cdc.nmic.cn/home.do). Annual precipitation was accumulated by summing the monthly precipitation at each station.

\subsection{Methodology}

GWR represents a local regression method in which the relationships between variables change with spatial position, and nonstationary relationships between dependent and explanatory variables are effectively considered [40]. Moreover, we selected the adaptive bi-square as the kernel function, and the small sample bias-corrected Akaike's information criterion (AICc) as the criteria [40]. This study used EVI, DEM, and TRMM data to establish a GWR model, where the GWR equation is expressed as follows:

$$
P_{\mathrm{LR}}=\beta_{0}\left(u_{j}, v_{j}\right)+\beta_{\mathrm{EVI}}\left(u_{j}, v_{j}\right) \mathrm{EVI}_{\mathrm{LR}}+\beta_{\mathrm{DEM}}\left(u_{j}, v_{j}\right) \mathrm{DEM}_{\mathrm{LR}}+\varepsilon_{\mathrm{LR}}\left(u_{j}, v_{j}\right)
$$

where $P_{\mathrm{LR}}, \mathrm{EVI}_{\mathrm{LR}}$ and $\mathrm{DEM}_{\mathrm{LR}}$ represent the TRMM annual precipitation, EVI, and elevation at a low resolution (LR) of $0.25^{\circ}$, respectively; $\left(u_{j}, v_{j}\right)$ is the geographical position, where $u_{j}$ represents the longitude and $v_{j}$ represents the latitude; $\beta_{0}\left(u_{j}, v_{j}\right)$ is the intercept; $\beta_{\mathrm{EVI}}\left(u_{j}, v_{j}\right)$ and $\beta_{\mathrm{DEM}}\left(u_{j}, v_{j}\right)$ are the slopes of precipitation with respect to the EVI and the DEM, respectively; and $\varepsilon_{\mathrm{LR}}\left(u_{j}, v_{j}\right)$ is the residual at a $0.25^{\circ}$ spatial resolution. The reader is referred to the literature for a more detailed introduction to the GWR method $[27,41,42]$.

This study assumed that the spatial heterogeneity of precipitation can be explained by two environmental variables, namely, the EVI and DEM. Based on the GWR model, functional relationships were established between the TRMM data and the EVI and DEM to downscale the TRMM precipitation. The main steps of the downscaling process are as follows:

1. Monthly TRMM precipitation data during the period 2000-2016 are accumulated to obtain the annual precipitation data, the monthly $\mathrm{EVI}_{1 \mathrm{~km}}$ is averaged to obtain the annual $\mathrm{EVI}_{1 \mathrm{~km}}$, and the $1-\mathrm{km}$ resolution EVI and DEM data are resampled to a $0.25^{\circ}$ resolution by bilinear interpolation. The model parameters in Equation (1), namely, $\beta_{0}\left(u_{j}, v_{j}\right), \beta_{\mathrm{EVI}}\left(u_{j}, v_{j}\right)$ and $\beta_{\mathrm{DEM}}\left(u_{j}, v_{j}\right)$, are obtained at a spatial resolution of $0.25^{\circ}$ by using the GWR model;

2. The model parameters, namely, $\beta_{0}\left(u_{j}, v_{j}\right), \beta_{\mathrm{EVI}}\left(u_{j}, v_{j}\right)$, and $\beta_{\mathrm{DEM}}\left(u_{j}, v_{j}\right)$, are resampled to $1 \mathrm{~km}$ using bilinear interpolation, where $\beta_{0}^{1 k m}\left(u_{j}, v_{j}\right), \beta_{\mathrm{EVI}}^{1 k m}\left(u_{j}, v_{j}\right)$, and $\beta_{\mathrm{EVI}}^{1 k m}\left(u_{j}, v_{j}\right)$ represent the model parameters at a $1-\mathrm{km}$ resolution;

3. The annual precipitation is estimated at a $1-\mathrm{km}$ resolution by using the $1-\mathrm{km}$ model parameters obtained in the previous step with the following equation:

$$
P_{e s t i m a t e d}^{1 k m}\left(u_{j}, v_{j}\right)=\beta_{0}^{1 k m}\left(u_{j}, v_{j}\right)+\beta_{\mathrm{EVI}}^{1 k m}\left(u_{j}, v_{j}\right) \operatorname{EVI}_{1 k m}+\beta_{\mathrm{DEM}}^{1 k m}\left(u_{j}, v_{j}\right) \operatorname{DEM}_{1 k m}
$$


4. The residual $\varepsilon_{\mathrm{LR}}\left(u_{j}, v_{j}\right)$ at a $0.25^{\circ}$ resolution is interpolated into a resolution of $1 \mathrm{~km}$ using ordinary kriging [43], the result of which is expressed as $\varepsilon^{1 k m}\left(u_{j}, v_{j}\right)$. Then, the downscaled precipitation is obtained by adding the $1-\mathrm{km}$ precipitation estimated in the previous step to the residual $\varepsilon^{1 k m}\left(u_{j}, v_{j}\right)$, and the result can be expressed as follows:

$$
P_{\text {downscaled }}^{1 k m}\left(u_{j}, v_{j}\right)=P_{\text {estimated }}^{1 k m}\left(u_{j}, v_{j}\right)+\varepsilon^{1 k m}\left(u_{j}, v_{j}\right)
$$

5. The geographical differential analysis (GDA) method proposed by Cheema et al. [44], based on residual merging algorithms for multisource data, is used to reduce the difference between the observation data and the downscaled precipitation data [45]. The difference $P_{\text {error }}^{\text {point }}$ between the downscaled precipitation data and the corresponding meteorological observation data is

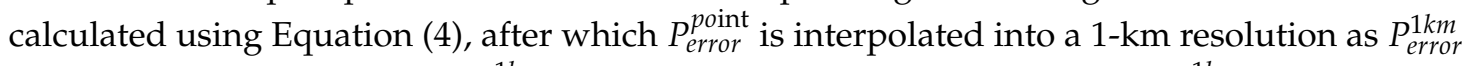
using ordinary kriging. Then, $P_{\text {error }}^{1 \mathrm{~km}}$ is subtracted from the downscaled data $P_{\text {downscaled }}^{1 \mathrm{~km}}$ to obtain the downscaled and calibrated precipitation data $P_{G D A}^{1 k m}$ :

$$
P_{\text {error }}^{\text {point }}=P_{\text {downscaled }}^{1 k m}-P^{\text {point }}
$$

6. The fraction Fraction $i_{i}^{0.25^{\circ}}$ is obtained by calculating the ratio of the monthly TRMM 3B43 precipitation data to the annual precipitation as follows [46]:

$$
\text { Fraction }_{i}^{0.25^{\circ}}=\frac{\text { TRMM }_{i}}{\sum_{i=1}^{12} \operatorname{TRMM}_{i}}
$$

where $\mathrm{TRMM}_{i}$ represents the original TRMM precipitation at a $0.25^{\circ}$ resolution in the $i$ th month of the year, and the denominator is the corresponding annual precipitation;

7. Ordinary kriging interpolation is employed to interpolate the fraction Fraction ${ }_{i}^{0.25^{\circ}}$ of each month into gridded data Fraction ${ }_{i}^{1 \mathrm{~km}}$ at a 1-km resolution. Finally, the fraction Fraction ${ }_{i}^{1 \mathrm{~km}}$ is multiplied by the annual downscaled data obtained in the fifth step, and the precipitation data of each month in 2000-2016 are obtained. The main steps of the downscaling method are shown in Figure 2. 


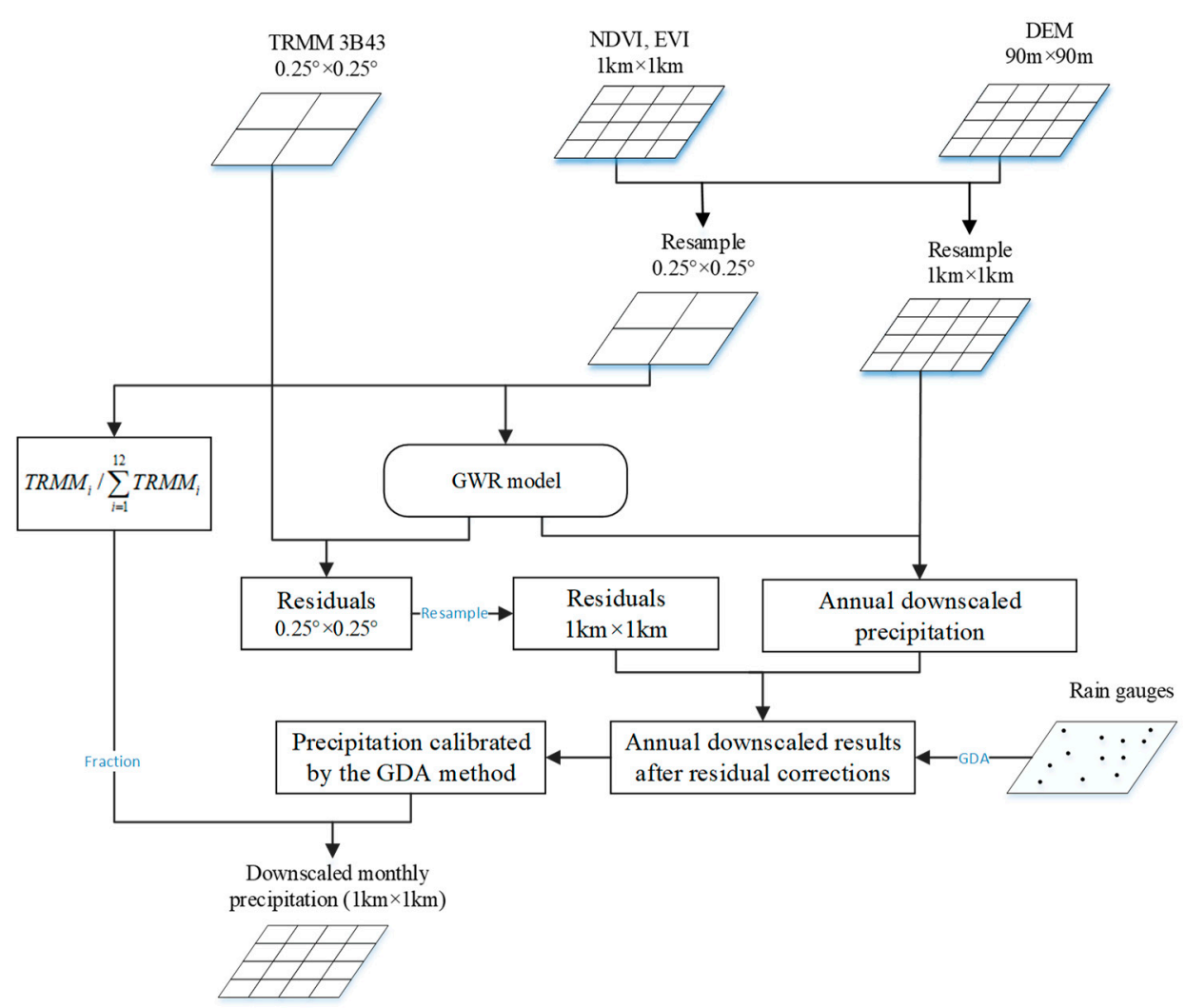

Figure 2. Flow chart of the geographically weighted regression (GWR)-based downscaling method proposed in the study.

\subsection{Validation}

We used data from weather stations that were not used for the calibration step to verify the downscaling results. The coefficients of determination $\left(R^{2}\right)$, the root mean squared error (RMSE), and the mean absolute error (MAE) were selected to evaluate the results:

$$
\begin{gathered}
R^{2}=\frac{\sum_{i=1}^{n}\left[\left(P_{i}-\bar{P}\right)\left(O_{i}-\bar{O}\right)\right]}{\sqrt{\sum_{i=1}^{n}\left(P_{i}-\bar{P}\right)^{2}} \sqrt{\sum_{i=1}^{n}\left(O_{i}-\bar{O}\right)^{2}}}, \\
\text { RMSE }=\sqrt{\frac{\sum_{i=1}^{n}\left(P_{i}-O_{i}\right)^{2}}{n}}, \\
\text { MAE }=\frac{\sum_{i=1}^{n}\left|P_{i}-O_{i}\right|}{n},
\end{gathered}
$$

where $P$ is the precipitation calculated by the downscaled results, and $O$ is the precipitation observed at the weather stations. $R^{2}$ represents the correlation between variables. The larger the $R^{2}$ value, the higher the correlation, and vice versa. The RMSE is used to measure the deviation between the predicted value and the true value. A higher RMSE value indicates a larger prediction bias, and vice versa. MAE is the average of absolute errors, avoiding positive and negative cancellation. The smaller the MAE value, the higher the prediction accuracy of the model.

\section{Results and Discussion}

\subsection{Comparison between the NDVI-Based and EVI-Based GWR Models}

In this study, the year of 2016 was selected to show the main results of the downscaling process. To investigate the efficiencies of the NDVI-based and EVI-based GWR models, the NDVI-derived 
and EVI-derived GWR annual downscaling models were established at a spatial resolution of $0.25^{\circ}$, and the downscaled results from 2000 to 2016 were obtained according to steps (1) through (4) of the abovementioned downscaling procedure. Figure 3 shows a comparison between the downscaling results from the NDVI-based and EVI-based GWR models. Evidently, regardless of whether the NDVI-based or EVI-based method was used, the accuracy of the downscaling results was better than that of the original TRMM data, thereby validating the applicability of the constructed downscaling models in the MLRYRB. In addition, a comparison between the box plots of the NDVI and EVI (where the NDVI-based box plots and EVI-based box plots are shown in green and blue, respectively) revealed that the NDVI performed better than the EVI in the annual downscaling model. At present, there have been few studies on the EVI-based downscaling model. Zhang et al. [30] used the EVI to estimate $\mathrm{PM}_{2.5}$ in the GWR model and concluded that the use of EVI could more effectively estimate $\mathrm{PM}_{2.5}$ than the previous GWR models, mainly because EVI is not easy to saturate even when the chlorophyll content is high. Although studies have shown that the NDVI is prone to supersaturation when the precipitation exceeds a certain threshold, this study used the annual NDVI average, which may have neutralized this saturation effect. This could explain the observed superiority of the NDVI. Therefore, in the following analysis, we employed the NDVI-based GWR annual precipitation downscaling model.

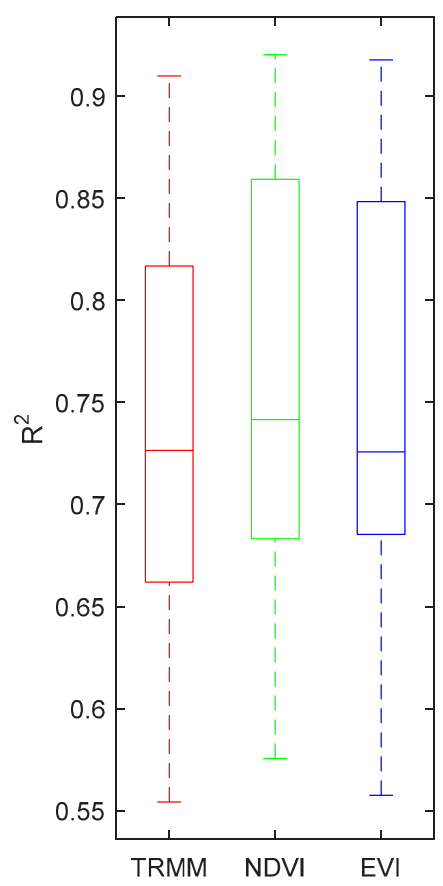

(a)

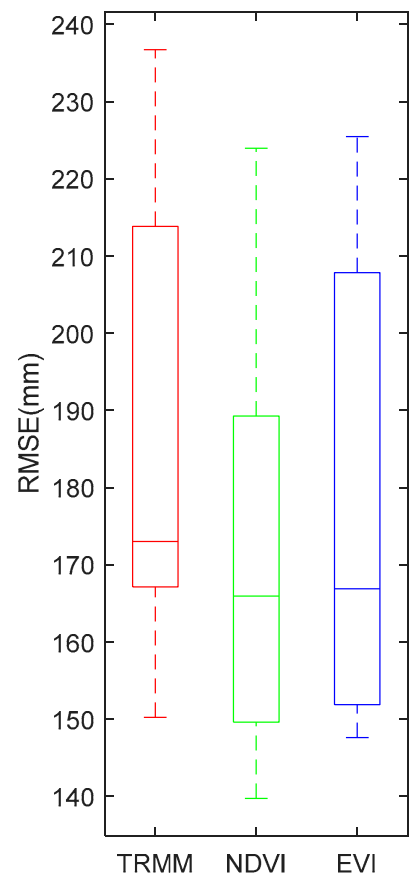

(b)

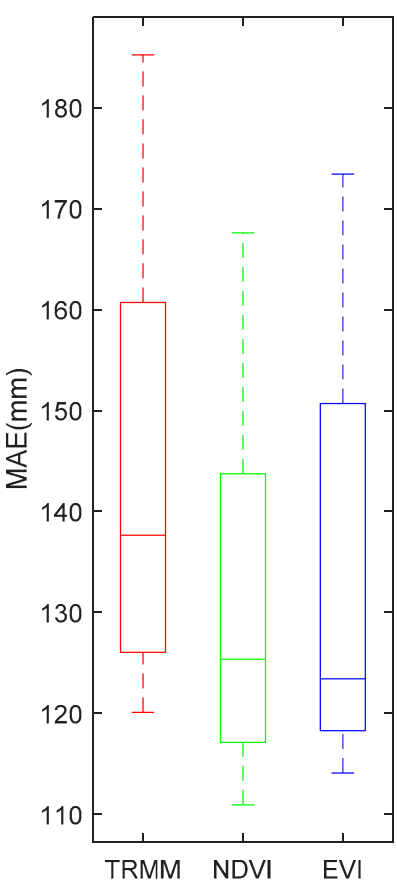

(c)

Figure 3. Comparison of the accuracies of the downscaled annual precipitation results between the normalized difference vegetation index (NDVI)-based and the enhanced vegetation index (EVI)-based GWR models. (a) $\mathrm{R}^{2}$; (b) RMSE; and (c) MAE.

\subsection{The Annual Downscaled Results and Ground Validation}

The spatial distribution of the annual precipitation based on the TRMM data in the MLRYRB is shown in Figure 4a. Based on the original TRMM data, the NDVI-derived downscaled results after correcting the residuals in the MLRYRB were obtained following the GWR-based downscaling procedure (Figure $4 \mathrm{~b}$ ). In addition, by utilizing the GDA calibration method, the difference between the meteorological station observation data (that is, the weather station data used for the calibration) and the 1-km downscaled results at each corresponding position was calculated and then interpolated into 1-km resolution data using ordinary kriging (Figure 4c). Finally, the annual downscaling data calibrated by the GDA method were obtained (Figure 4d). 

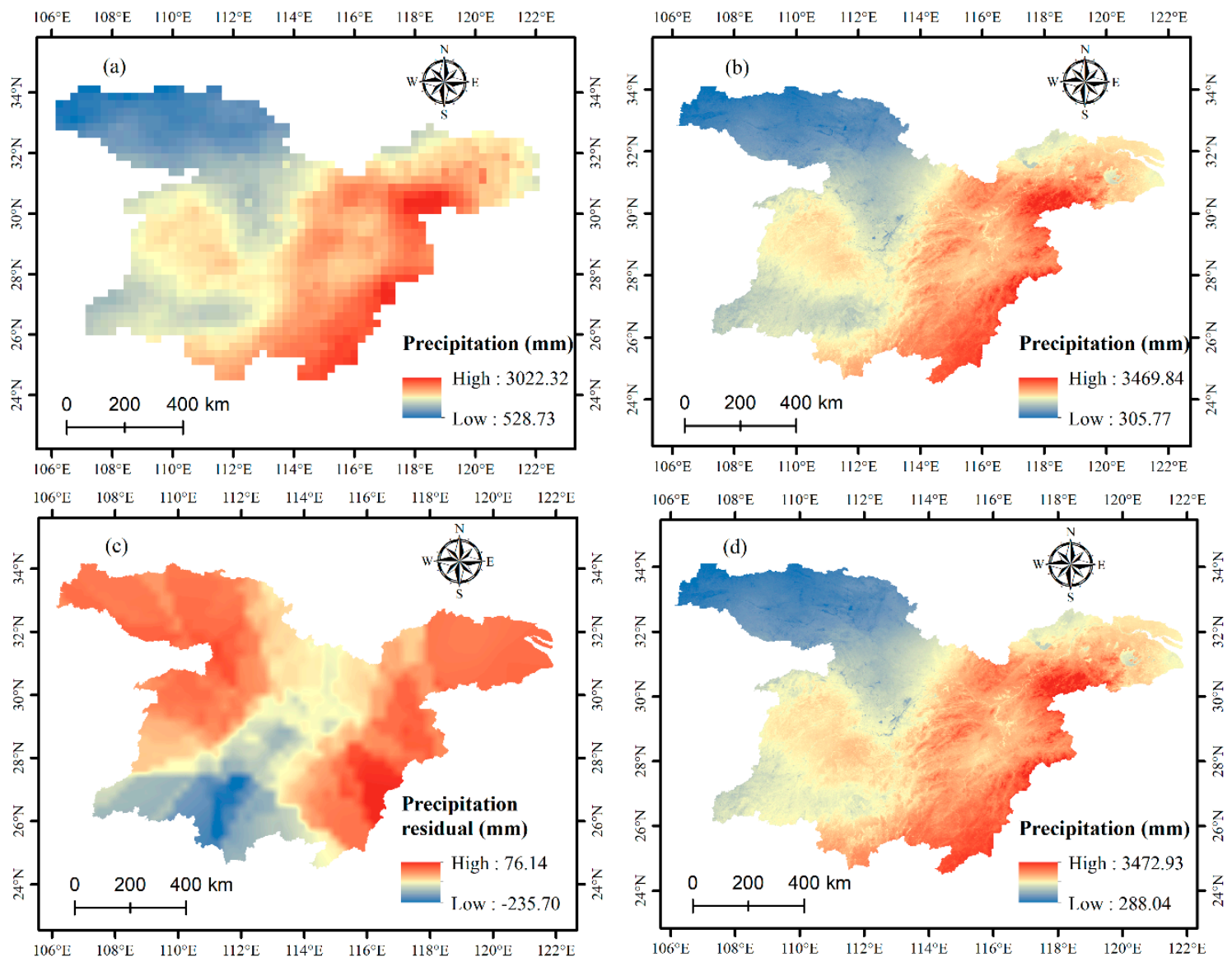

Figure 4. (a) Annual Tropical Rainfall Measuring Mission (TRMM) precipitation data over the MLRYRB for 2016 at a $0.25^{\circ}$ resolution; (b) downscaled results after residual corrections for 2016 in the MLRYRB; (c) interpolated residuals using ordinary kriging; (d) annual downscaled precipitation calibrated by the geographical differential analysis (GDA) method.

Figure $4 \mathrm{a}, \mathrm{b}$ showed that the original TRMM precipitation data were consistent with the residual-corrected precipitation distributions, and the $R^{2}$ of the results downscaled with GWR was 0.91, indicating that the GWR method could downscale the TRMM annual precipitation data from $0.25^{\circ} \times 0.25^{\circ}$ to $1 \mathrm{~km} \times 1 \mathrm{~km}$ over the MLRYRB. The variation range of the original TRMM precipitation was 528.73-3022.32 $\mathrm{mm}$ (Figure 4a), while the downscaled precipitation range after the residual correction was 305.77-3469.84 mm (Figure 4b). The downscaled precipitation clearly contained more detail and better reflected the spatial variations in the precipitation. In addition, the residual variation range was $-235.70-76.14 \mathrm{~mm}$ (Figure $4 \mathrm{c}$ ), where red indicates a slight overestimation of rainfall, blue indicates an underestimation, and yellow indicates a very accurate rainfall estimate at the weather stations.

To test the performance of the constructed downscaled model, we compared the downscaled results with remaining weather station data during the period 2000-2016. Figure 5a shows scatterplots of the TRMM data and the weather station observation data, where the $R^{2}$, RMSE, and MAE values were $0.86,180.52 \mathrm{~mm}$, and $146.44 \mathrm{~mm}$, respectively. The original TRMM data overestimated precipitation in comparison with the rain gauge observations. However, before the residual corrections, the $R^{2}$, RMSE, and MAE values were $0.75,200.42 \mathrm{~mm}$, and $153.97 \mathrm{~mm}$, respectively (Figure 5b). Prior to performing the residual corrections, the spatial resolution clearly improved from $0.25^{\circ}$ to $1 \mathrm{~km}$, but the accuracy was not as good as that of the TRMM data. Figure $5 \mathrm{c}$ illustrates that, after the residual corrections, the $R^{2}$ increased by 0.12 , the RMSE value was reduced by $53.96 \mathrm{~mm}$, and the MAE value decreased by $36.79 \mathrm{~mm}$. Hence, the accuracy of the downscaling model could be effectively 
improved after correcting for residuals, thereby verifying the importance of residual corrections in the downscaling model for the MLRYRB. After calibration with the GDA method, the downscaled rainfall was more similar to the actual rainfall observations from the weather stations $\left(R^{2}=0.88\right.$, RMSE $=140.56 \mathrm{~mm}$, and MAE $=113.56 \mathrm{~mm})$. Thus, the calibration process was essential for acquiring more accurate downscaling results.
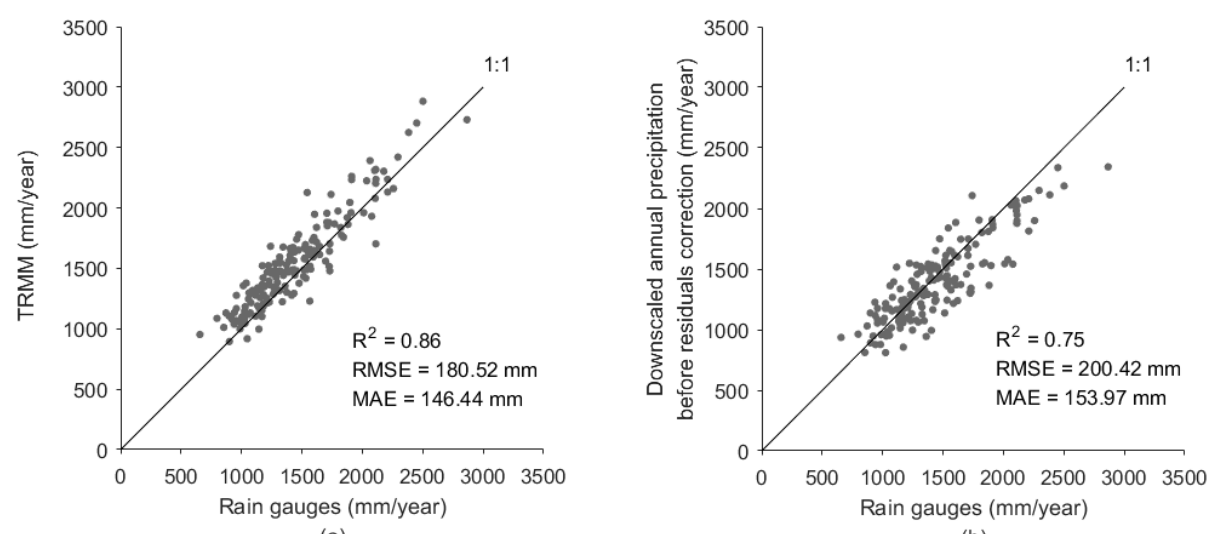

(a)

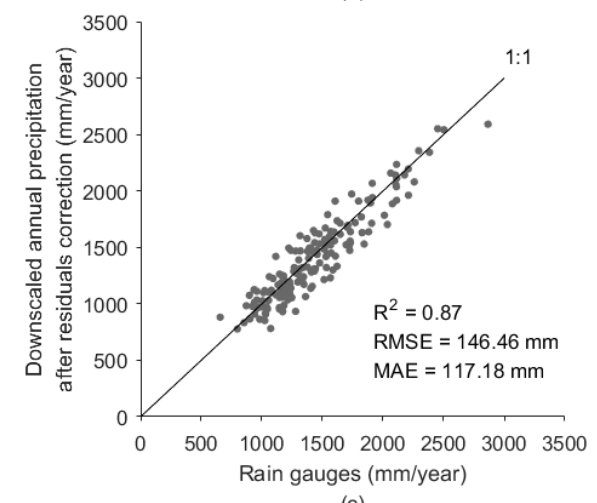

(c)

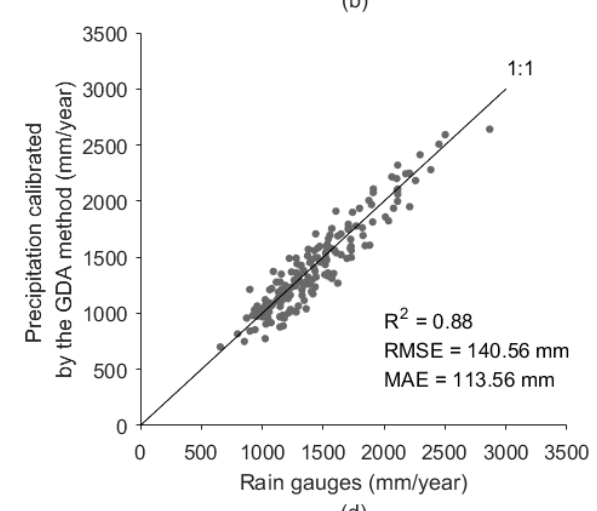

(d)

Figure 5. Scatterplots of the weather station precipitation observations and the TRMM data (a), the downscaled annual precipitation before residual corrections (b), the downscaled precipitation after residual corrections (c), and the precipitation calibrated by the GDA method (d) during the period 2000-2016.

\subsection{Downscaled Monthly Precipitation Results}

According to the preceding downscaled steps, the annual downscaled results within the MLRYRB were decomposed to obtain downscaled precipitation data with a spatial resolution of $1 \mathrm{~km}$ on a monthly scale (Figure 6). Figure 6 shows the original $0.25^{\circ}$ resolution TRMM data from January to December and the downscaled precipitation data with a spatial resolution of $1 \mathrm{~km}$ for each corresponding month. The results showed that the TRMM data and the downscaled results had similar overall spatial distributions, but the downscaling results had a higher resolution and thus could display more detailed information.

Table 1 shows a comparison between the monthly precipitation accuracies. The results showed that the mean $R^{2}$, RMSE, and MAE values between the monthly precipitation data and the weather station observations based on the calibrated downscaling procedure were $0.86,34.63 \mathrm{~mm} / \mathrm{month}$, and $23.12 \mathrm{~mm} /$ month, respectively, while those between the original TRMM precipitation and weather station observations were $0.85,38.01 \mathrm{~mm} / \mathrm{month}$, and $25.69 \mathrm{~mm} / \mathrm{month}$, respectively. These results showed that the downscaled method proposed in this study could improve not only the spatial resolution of remote sensing precipitation data but also the accuracy of the data through the GDA method. Furthermore, the proposed approach can provide a theoretical basis for obtaining precipitation data with high spatial resolution. 

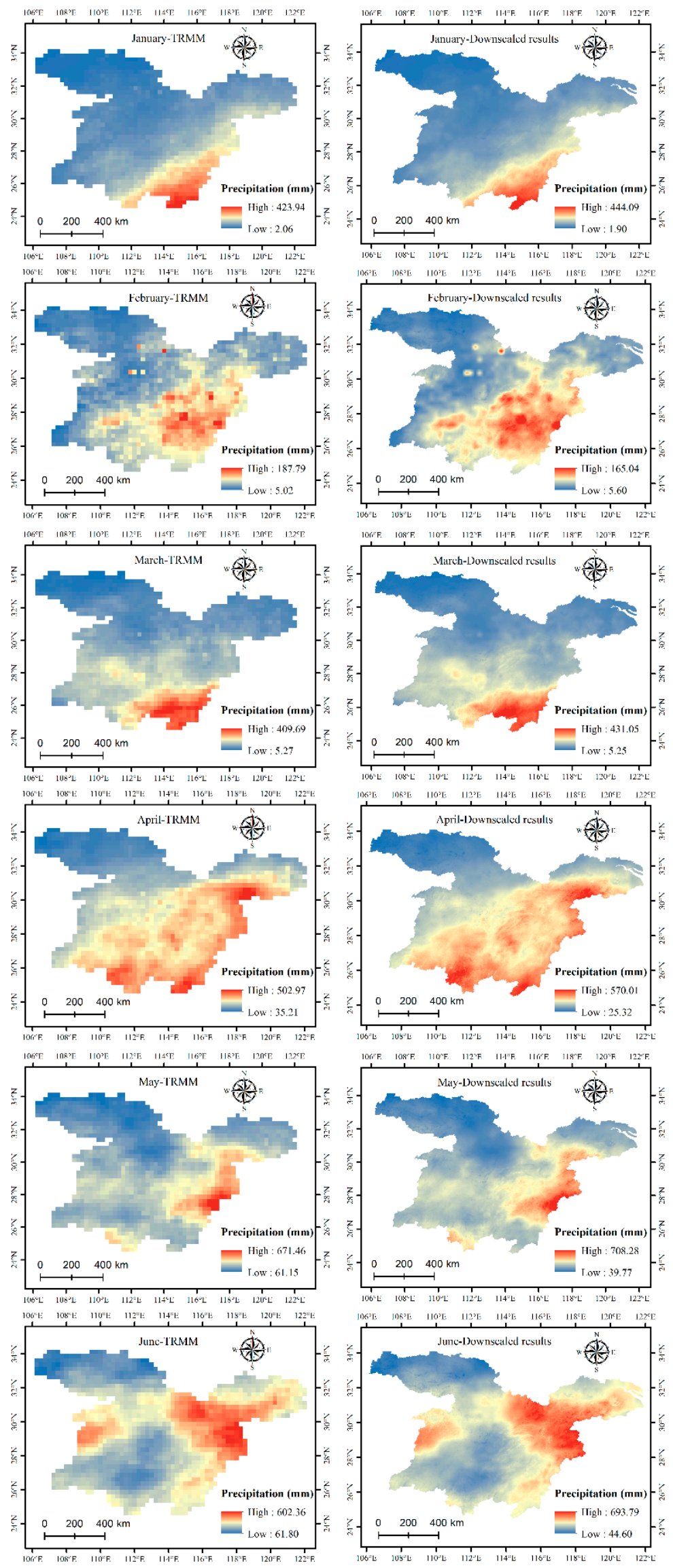

Figure 6. Cont. 

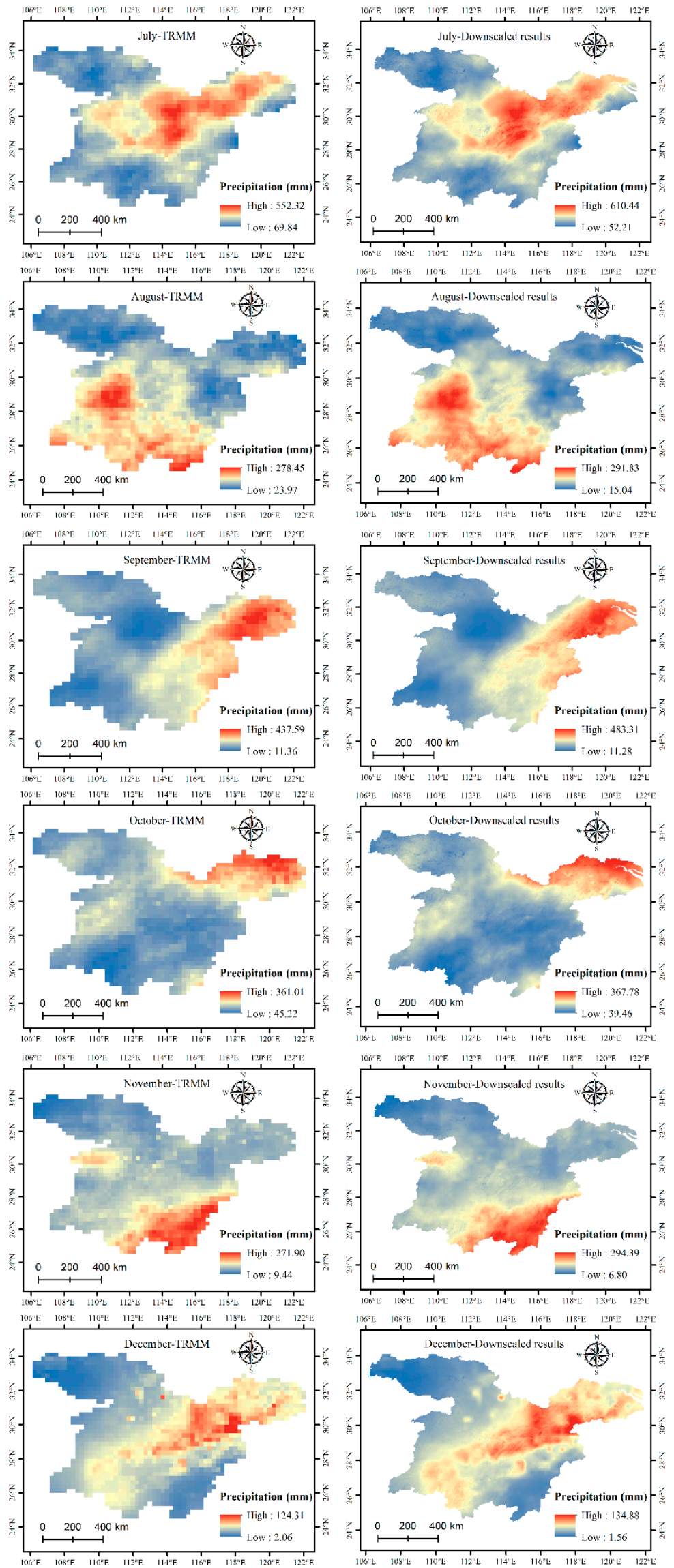

Figure 6. Spatial distributions of the original $0.25^{\circ}$ resolution TRMM data and the downscaled precipitation data with a 1-km spatial resolution from January to December 2016 over the MLRYRB. 
Table 1. Comparison between the TRMM original resolution data $\left(0.25^{\circ} \times 0.25^{\circ}\right)$ versus the weather stations. RMSE: Root mean squared error; MAE: Mean absolute error.

\begin{tabular}{cccccccccc}
\hline \multirow{2}{*}{$\begin{array}{c}\text { Weather } \\
\text { Station Name }\end{array}$} & \multirow{2}{*}{ Longitude } & \multirow{2}{*}{ Latitude } & \multirow{2}{*}{ Elevation } & \multicolumn{3}{c}{ TRMM } & \multicolumn{3}{c}{ Downscaled Results } \\
\cline { 5 - 9 } & & & & $\boldsymbol{R}^{\mathbf{2}}$ & RMSE & MAE & $\boldsymbol{R}^{\mathbf{2}}$ & RMSE & MAE \\
\hline Yichang & 111.30 & 30.70 & 105 & 0.90 & 29.73 & 20.18 & 0.90 & 25.80 & 16.99 \\
Wuhan & 114.13 & 30.62 & 14 & 0.91 & 28.85 & 18.72 & 0.93 & 26.23 & 17.89 \\
Yueyang & 113.08 & 29.38 & 19 & 0.78 & 42.26 & 31.44 & 0.84 & 32.48 & 22.83 \\
Anhua & 111.22 & 28.38 & 201 & 0.83 & 43.95 & 26.66 & 0.85 & 43.55 & 27.99 \\
Jian & 114.92 & 27.05 & 44 & 0.84 & 41.61 & 29.85 & 0.84 & 40.83 & 29.34 \\
Wugang & 110.63 & 26.73 & 338 & 0.91 & 23.52 & 17.10 & 0.91 & 21.89 & 16.08 \\
Chenzhou & 113.03 & 25.80 & 179 & 0.86 & 37.51 & 25.38 & 0.87 & 35.52 & 23.45 \\
Chaohu & 117.87 & 31.62 & 21 & 0.74 & 44.40 & 28.14 & 0.76 & 41.68 & 23.05 \\
Boyang & 116.68 & 29.00 & 20 & 0.79 & 50.54 & 32.72 & 0.82 & 44.71 & 29.78 \\
Nancheng & 116.65 & 27.58 & 64 & 0.92 & 37.67 & 26.69 & 0.92 & 33.65 & 23.82 \\
\hline
\end{tabular}

\subsection{Comparison and Analysis of Downscaling Results of TRMM and GPM Data}

TRMM data have been widely used in a series of satellite remote sensing precipitation products. As an extension of TRMM satellite precipitation products, GPM data have a resolution of $10 \mathrm{~km}$ in comparison with the $0.25^{\circ}$ resolution (approximately $27 \mathrm{~km}$ ) of TRMM data, and some studies have shown that the accuracy of the former data is also better than that of the TRMM data [47]. Because GPM data begin in March 2014, GPM products suffer from a short time series. However, as NASA's GPM mission continues to provide long-range products, we will be able to obtain high-resolution and long series of satellite remote sensing precipitation products in the future. Here, we chose a complete year (2016) as an example to compare and analyze the downscaling performance of TRMM data with that of GPM data over the MLRYRB.

Figure 7 illustrates the spatial distribution of the TRMM precipitation data $\left(0.25^{\circ} \times 0.25^{\circ}\right)$ and GPM precipitation data $(10 \mathrm{~km} \times 10 \mathrm{~km})$. To further analyze the accuracies of these data, we selected 60 meteorological stations to analyze the downscaling accuracy of these two data sources. Figure 8 displays scatterplots of the meteorological station observation data and the TRMM and GPM datasets. The results showed that the $R^{2}$ of the GPM data was 0.83 , which was better than that of the TRMM data, but the MAE and RMSE values of the GPM data were slightly higher than those of the TRMM data. The results of the three indices (MAE, $R^{2}$, and RMSE) suggest that the accuracy of the TRMM and GPM in modeling annual precipitation in the MLRYRB was comparable. The $R^{2}$ indicated GPM was more efficient than TRMM, whereas the RMSE and MAE showed that the TRMM was quite better.
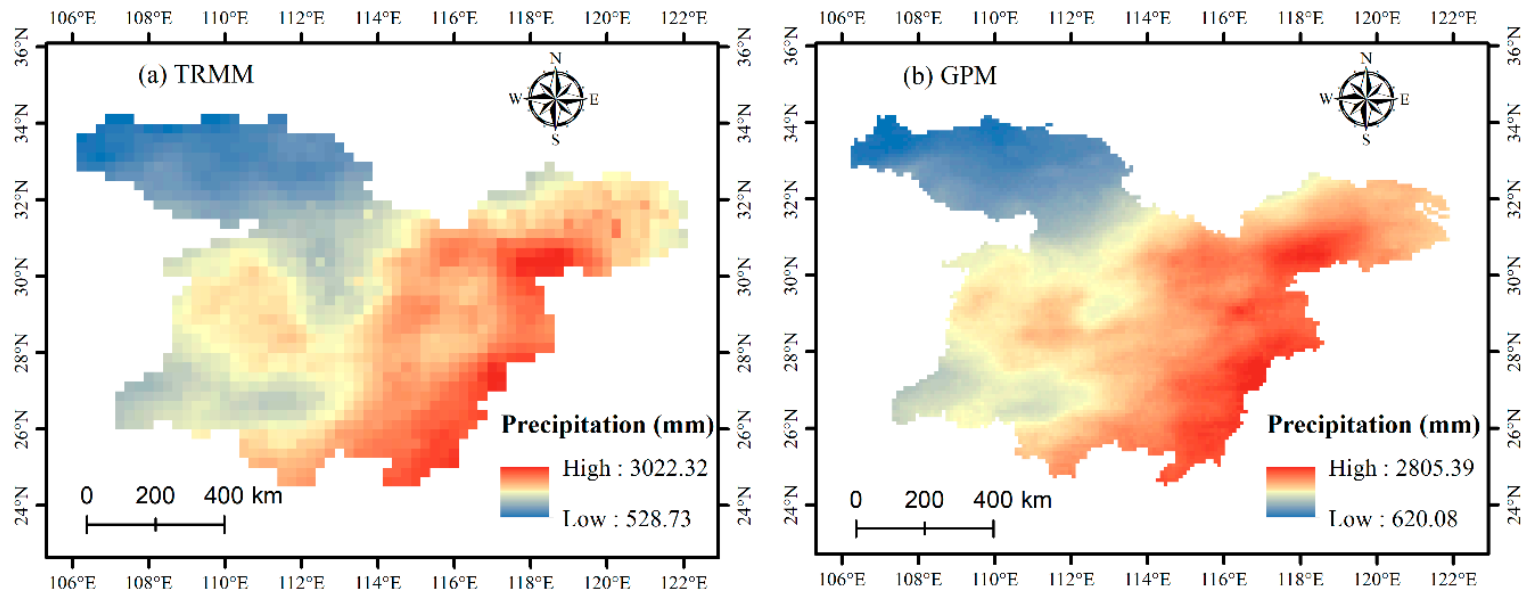

Figure 7. Spatial distributions of the TRMM precipitation data $\left(0.25^{\circ} \times 0.25^{\circ}\right)(\mathbf{a})$ and GPM precipitation data $(10 \mathrm{~km} \times 10 \mathrm{~km})(\mathbf{b})$ in 2016 over the MLRYRB. 


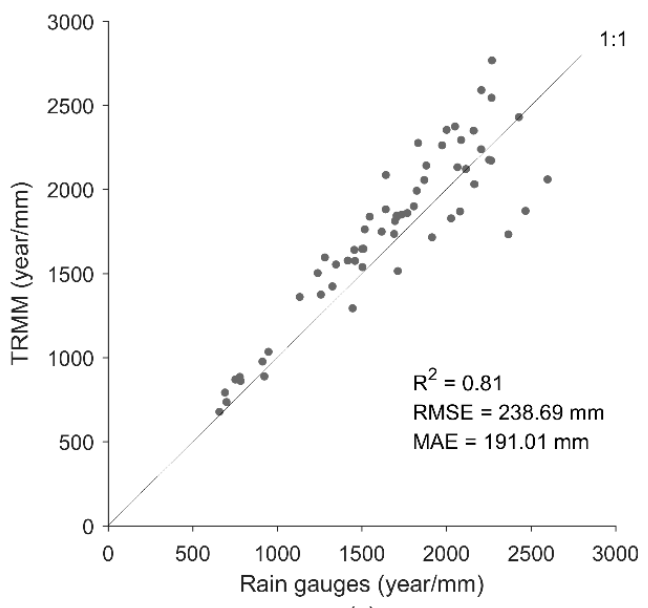

(a)

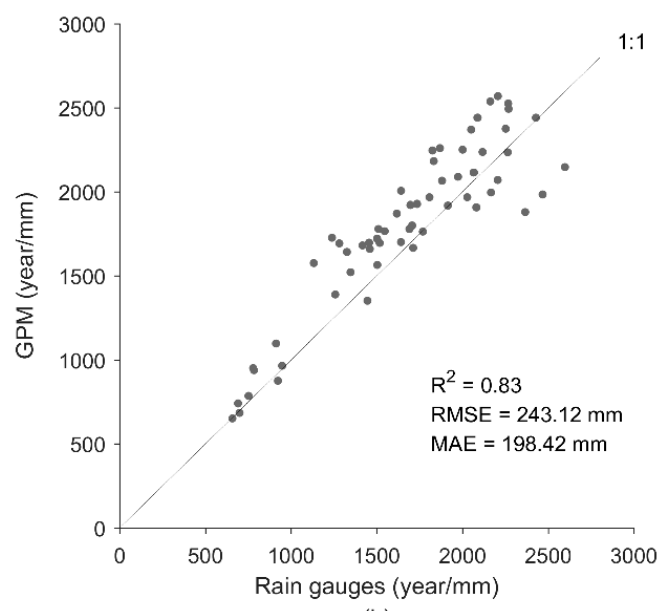

(b)

Figure 8. Scatterplots of the meteorological station observation data and (a) the original TRMM data $\left(0.25^{\circ} \times 0.25^{\circ}\right)$ and $(\mathbf{b})$ the original GPM data $(10 \mathrm{~km} \times 10 \mathrm{~km})$.

According to steps (1) through (4) of the downscaling procedure, the GPM precipitation data were downscaled and compared to the downscaled TRMM precipitation data in Figure 9 for the year of 2016. The spatial distribution trends of the two data sources were similar, but the downscaled results for the MLRYRB based on the TRMM data ranged approximately from 305.77 to $3469.84 \mathrm{~mm}$, while those based on the GPM data ranged approximately from 227.26 to $2844.65 \mathrm{~mm}$. To validate the results, we plotted scatterplots of the two data sources and the weather station observations in Figure 10. The results showed that the $R^{2}$ and RMSE values of the GPM precipitation data $\left(R^{2}=0.87\right.$ and $\mathrm{RMSE}=183.88 \mathrm{~mm}$ ) were generally better than the TRMM precipitation data, but the MAE value of the former $(\mathrm{MAE}=153.06 \mathrm{~mm}$ ) was slightly larger than that of the latter precipitation product. The RMSE and MAE values of the GPM data were higher than the TRMM data before downscaling, and the RMSE of the GPM data was lower than the TRMM data after downscaling. Since NASA's GPM mission will continue to provide GPM remote sensing precipitation products, there will be more years with which to compare and analyze the differences between these two data sources when the time series are longer.
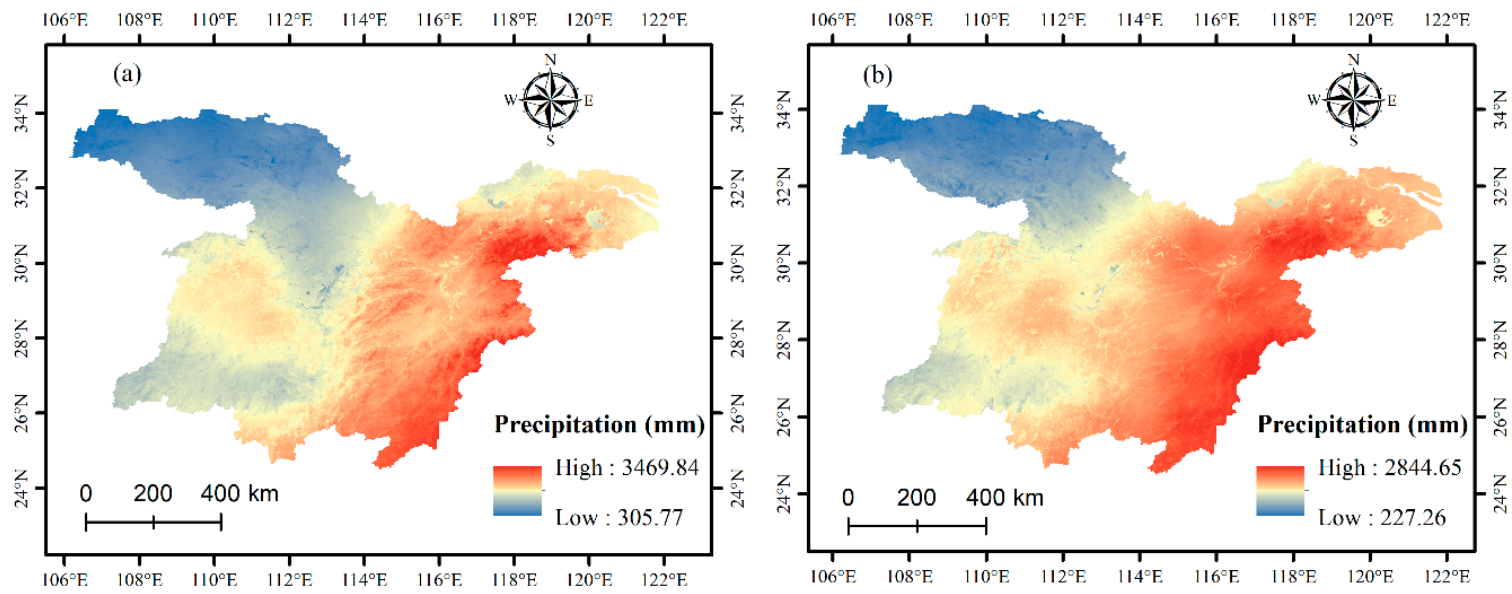

Figure 9. Spatial distributions of the downscaled results with the TRMM precipitation data $\left(0.25^{\circ} \times 0.25^{\circ}\right)(\mathbf{a})$ and GPM precipitation data $(10 \mathrm{~km} \times 10 \mathrm{~km})(\mathbf{b})$ in 2016 over the MLRYRB. 


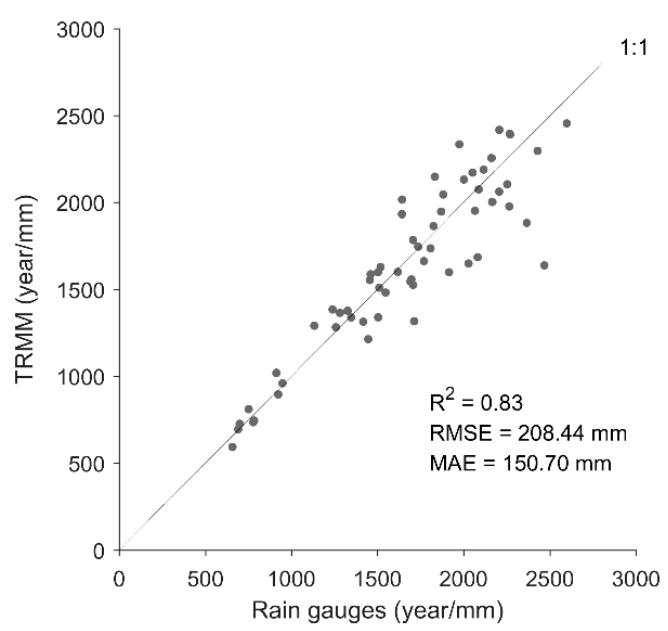

(a)

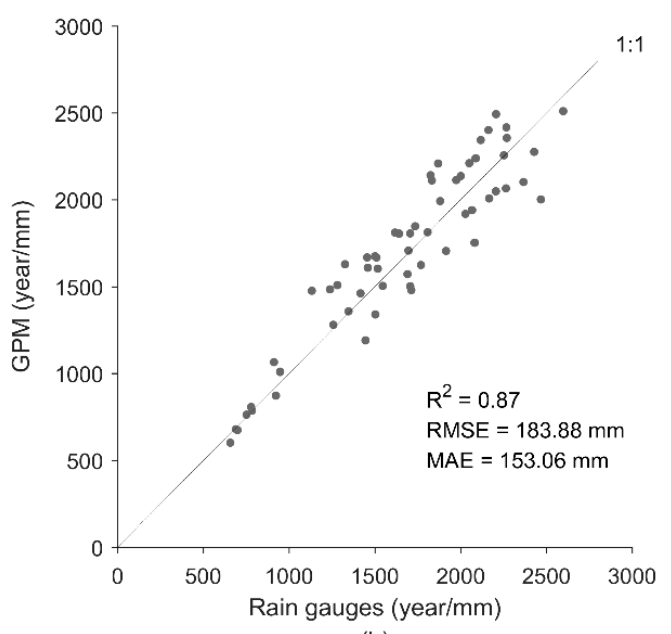

(b)

Figure 10. Scatterplots of the validation of the meteorological station observation data and the downscaled results at $1 \mathrm{~km}$ resolution based on (a) the TRMM data and (b) the GPM data.

\section{Conclusions}

In this study, we used a GWR-based downscaling model to downscale TRMM 3B43 precipitation data from a resolution of $0.25^{\circ}$ to $1 \mathrm{~km}$ on an annual scale in the MLRYRB. The 1-km residual-corrected model based on the GWR method was then used to calculate the precipitation data, after which the annual downscaled results were calibrated by the GDA method. Then, the calibrated 1-km annual precipitation data were decomposed into fractions to obtain monthly precipitation data from 2000 to 2016 over the MLRYRB. The main conclusions can be summarized as follows:

(1) We compared the accuracies of the annual downscaled results acquired with the NDVI-based and EVI-based GWR models, showing that the NDVI performed better than the EVI in the annual downscaling model. This may have been because this study used the annual average NDVI, which may have neutralized any detrimental saturation effects;

(2) The accuracy of the downscaling model could be effectively improved after correcting the residuals and performing a calibration with the GDA method. Subsequently, the calculated rainfall was closer to the actual weather station rainfall observations $\left(R^{2}=0.88\right.$, RMSE $=140.56 \mathrm{~mm}$, and MAE $=113.56 \mathrm{~mm}$ ). Thus, the calibration process was essential in providing more accurate downscaling results;

(3) The downscaled results were decomposed into fractions to obtain monthly precipitation data. The downscaled method proposed in this study could improve not only the spatial resolution of remote sensing precipitation data, but also the accuracy of such data, by utilizing the GDA method;

(4) Finally, we analyzed and compared the downscaling performance of TRMM data to GPM data over the MLRYRB. The results showed that the $R^{2}$ and RMSE values of the GPM precipitation data $(R 2=0.87$ and RMSE $=183.88 \mathrm{~mm})$ were generally better than the TRMM precipitation data, but the MAE value of the former $(\mathrm{MAE}=153.06 \mathrm{~mm})$ was slightly larger than that of the latter.

Author Contributions: For conceptualization, S.C. and L.Z.; methodology, S.C.; software, S.C.; validation, L.Z., D.S. and J.C.; formal analysis, S.C.; investigation, S.C.; resources, S.C.; data curation, S.C.; writing-original draft preparation, S.C.; writing-review and editing, L.Z., D.S. and J.C.; visualization, D.S.; supervision, L.Z.; project administration, J.C.; funding acquisition, L.Z.

Funding: This study was supported by the National Key Research and Development Program of China (NO.2017YFA0603704).

Acknowledgments: Thanks to the Earth Observing System Data Gateway of the United States National Aeronautics and Space Administration (NASA) (https:/ / earthdata.nasa.gov/) for offering the MODIS data. The 
meteorological data used in this study were collected from the National Climatic Centre of China Meteorological Administration (available on http://cdc.nmic.cn/home.do), which was highly appreciated. We are very grateful to the editor and anonymous reviewers.

Conflicts of Interest: The authors declare no conflicts of interest.

\section{References}

1. Ma, Z.; Shi, Z.; Zhou, Y.; Xu, J.; Yu, W.; Yang, Y. A spatial data mining algorithm for downscaling TMPA 3B43 V7 data over the Qinghai-Tibet Plateau with the effects of systematic anomalies removed. Remote Sens. Environ. 2017, 200, 378-395. [CrossRef]

2. Li, M.; Shao, Q. An improved statistical approach to merge satellite rainfall estimates and raingauge data. J. Hydrol. 2010, 385, 51-64. [CrossRef]

3. Shi, Y.; Song, L.; Xia, Z.; Lin, Y.; Myneni, R.; Choi, S.; Wang, L.; Ni, X.; Lao, C.; Yang, F. Mapping annual precipitation across mainland China in the period 2001-2010 from TRMM3B43 product using spatial downscaling approach. Remote Sens. 2015, 7, 5849-5878. [CrossRef]

4. Xu, G.; Xu, X.; Liu, M.; Sun, A.; Wang, K. Spatial downscaling of TRMM precipitation product using a combined multifractal and regression approach: Demonstration for South China. Water 2015, 7, 3083-3102. [CrossRef]

5. Mahesh, C.; Prakash, S.; Sathiyamoorthy, V.; Gairola, R.M. Artificial neural network based microwave precipitation estimation using scattering index and polarization corrected temperature. Atmos. Res. 2011, 102, 358-364. [CrossRef]

6. Zhu, H.; Li, Y.; Huang, Y.; Li, Y.; Hou, C.; Shi, X. Evaluation and hydrological application of satellite-based precipitation datasets in driving hydrological models over the Huifa river basin in Northeast China. Atmos. Res. 2018, 207, 28-41. [CrossRef]

7. Behrangi, A.; Khakbaz, B.; Jaw, T.C.; AghaKouchak, A.; Hsu, K.; Sorooshian, S. Hydrologic evaluation of satellite precipitation products over a mid-size basin. J. Hydrol. 2011, 397, 225-237. [CrossRef]

8. Kubota, T.; Shige, S.; Hashizume, H.; Aonashi, K.; Takahashi, N.; Seto, S.; Hirose, M.; Takayabu, Y.N.; Ushio, T.; Nakagawa, K.; et al. Global precipitation map using satellite-borne microwave radiometers by the GSMaP project: Production and validation. IEEE Trans. Geosci. Remote Sens. 2007, 45, 2259-2275. [CrossRef]

9. Huffman, G.J.; Adler, R.F.; Arkin, P.; Chang, A.; Ferraro, R.; Gruber, A.; Janowiak, J.; McNab, A.; Rudolf, B.; Schneider, U. The global precipitation climatology project (GPCP) combined precipitation dataset. Bull. Am. Meteorol. Soc. 1997, 78, 5-20. [CrossRef]

10. Adler, R.F.; Huffman, G.J.; Chang, A.; Ferraro, R.; Xie, P.P.; Janowiak, J.; Rudolf, B.; Schneider, U.; Curtis, S.; Bolvin, D.; et al. The version-2 global precipitation climatology project (GPCP) monthly precipitation analysis (1979-present). J. Hydrometeorol. 2003, 4, 1147-1167. [CrossRef]

11. Huffman, G.J.; Bolvin, D.T.; Nelkin, E.J.; Wolff, D.B.; Adler, R.F.; Gu, G.; Hong, Y.; Bowman, K.P.; Stocker, E.F. The TRMM multisatellite precipitation analysis (TMPA): Quasi-global, multiyear, combined-sensor precipitation estimates at fine scales. J. Hydrometeorol. 2007, 8, 38-55. [CrossRef]

12. Su, F.; Hong, Y.; Lettenmaier, D.P. Evaluation of TRMM multisatellite precipitation analysis (TMPA) and its utility in hydrologic prediction in the La Plata Basin. J. Hydrometeorol. 2008, 9, 622-640. [CrossRef]

13. Sohn, B.J.; Han, H.-J.; Seo, E.-K. Validation of satellite-based high-resolution rainfall products over the Korean Peninsula using data from a dense rain gauge network. J. Appl. Meteorol. Climatol. 2010, 49, 701-714. [CrossRef]

14. Zhan, C.; Han, J.; Hu, S.; Liu, L.; Dong, Y. Spatial downscaling of GPM annual and monthly precipitation using regression-based algorithms in a mountainous area. Adv. Meteorol. 2018, 2018, 1506017. [CrossRef]

15. Zhang, Y.; Li, Y.; Ji, X.; Luo, X.; Li, X. Fine-resolution precipitation mapping in a mountainous watershed: Geostatistical downscaling of TRMM products based on environmental variables. Remote Sens. 2018, 10, 119. [CrossRef]

16. Jia, S.; Zhu, W.; Lû, A.; Yan, T. A statistical spatial downscaling algorithm of TRMM precipitation based on NDVI and DEM in the Qaidam Basin of China. Remote Sens. Environ. 2011, 115, 3069-3079. [CrossRef]

17. Immerzeel, W.W.; Rutten, M.M.; Droogers, P. Spatial downscaling of TRMM precipitation using vegetative response on the Iberian Peninsula. Remote Sens. Environ. 2009, 113, 362-370. [CrossRef] 
18. Ulloa, J.; Ballari, D.; Campozano, L.; Samaniego, E. Two-step downscaling of TRMM 3b43 V7 precipitation in contrasting climatic regions with sparse monitoring: The case of Ecuador in tropical South America. Remote Sens. 2017, 9, 758. [CrossRef]

19. Ezzine, H.; Bouziane, A.; Ouazar, D.; Hasnaoui, M.D. Downscaling of TRMM3B43 product through spatial and statistical analysis based on normalized difference water index, elevation, and distance from sea. IEEE Geosci. Remote Sens. Lett. 2017, 14, 1449-1453. [CrossRef]

20. Brunsdon, C.; McClatchey, J.; Unwin, D.J. Spatial variations in the average rainfall-altitude relationship in Great Britain: An approach using geographically weighted regression. Int. J. Climatol. 2001, 21, 455-466. [CrossRef]

21. Pettorelli, N.; Vik, J.O.; Mysterud, A.; Gaillard, J.M.; Tucker, C.J.; Stenseth, N.C. Using the satellite-derived NDVI to assess ecological responses to environmental change. Trends Ecol. Evol. 2005, 20, 503-510. [CrossRef] [PubMed]

22. Fang, J.; Du, J.; Xu, W.; Shi, P.; Li, M.; Ming, X. Spatial downscaling of TRMM precipitation data based on the orographical effect and meteorological conditions in a mountainous area. Adv. Water Resour. 2013, 61, 42-50. [CrossRef]

23. Foody, G.M. Geographical weighting as a further refinement to regression modelling: An example focused on the NDVI-rainfall relationship. Remote Sens. Environ. 2003, 88, 283-293. [CrossRef]

24. Gao, J.; Li, S. Detecting spatially non-stationary and scale-dependent relationships between urban landscape fragmentation and related factors using Geographically Weighted Regression. Appl. Geogr. 2011, 31, $292-302$. [CrossRef]

25. Brunsdon, C.; Fotheringham, A.S.; Charlton, M.E. Geographically weighted regression: A method for exploring spatial nonstationarity. Geogr. Anal. 1996, 28, 281-298. [CrossRef]

26. An, K.-J.; Lee, S.-W.; Hwang, S.-J.; Park, S.-R.; Hwang, S.-A. Exploring the non-stationary effects of forests and developed land within watersheds on biological indicators of streams using geographically-weighted regression. Water 2016, 8, 120. [CrossRef]

27. Li, S.; Zhao, Z.; Miaomiao, X.; Wang, Y. Investigating spatial non-stationary and scale-dependent relationships between urban surface temperature and environmental factors using geographically weighted regression. Environ. Model. Softw. 2010, 25, 1789-1800. [CrossRef]

28. Huete, A.; Didan, K.; Miura, T.; Rodriguez, E.P.; Gao, X.; Ferreira, L.G. Overview of the radiometric and biophysical performance of the MODIS vegetation indices. Remote Sens. Environ. 2002, 83, 195-213. [CrossRef]

29. Justice, C.O.; Vermote, E.; Townshend, J.R.G.; Defries, R.; Roy, D.P.; Hall, D.K.; Salomonson, V.V.; Privette, J.L.; Riggs, G.; Strahler, A.; et al. The Moderate Resolution Imaging Spectroradiometer (MODIS): Land remote sensing for global change research. IEEE Trans. Geosci. Remote Sens. 1998, 36, 1228-1249. [CrossRef]

30. Zhang, T.; Gong, W.; Wang, W.; Ji, Y.; Zhu, Z.; Huang, Y. Ground level PM2.5 estimates over China using satellite-based geographically weighted regression (GWR) models are improved by including $\mathrm{NO}_{2}$ and enhanced vegetation index (EVI). Int. J. Environ. Res. Public Health 2016, 13, 1215. [CrossRef] [PubMed]

31. Shi, Y.L.; Song, L. Spatial downscaling of monthly TRMM precipitation based on EVI and other geospatial variables over the Tibetan Plateau From 2001 to 2012. Mt. Res. Dev. 2015, 35, 180-194. [CrossRef]

32. Chen, S.; Zhang, L.; Liu, X.; Guo, M.; She, D. The Use of SPEI and TVDI to assess temporal-spatial variations in drought conditions in the middle and lower reaches of the Yangtze River Basin, China. Adv. Meteorol. 2018, 2018, 9362041. [CrossRef]

33. De Jesús, A.; Breña-Naranjo, J.; Pedrozo-Acuña, A.; Alcocer Yamanaka, V. The use of TRMM 3B42 product for drought monitoring in Mexico. Water 2016, 8, 325. [CrossRef]

34. Moazami, S.; Golian, S.; Kavianpour, M.R.; Hong, Y. Uncertainty analysis of bias from satellite rainfall estimates using copula method. Atmos. Res. 2014, 137, 145-166. [CrossRef]

35. Wallace, C.; Walker, J.; Skirvin, S.; Patrick-Birdwell, C.; Weltzin, J.; Raichle, H. Mapping presence and predicting phenological status of invasive buffelgrass in Southern Arizona using MODIS, climate and citizen science observation data. Remote Sens. 2016, 8, 524. [CrossRef]

36. Scharlemann, J.P.; Benz, D.; Hay, S.I.; Purse, B.V.; Tatem, A.J.; Wint, G.R.; Rogers, D.J. Global data for ecology and epidemiology: A novel algorithm for temporal Fourier processing MODIS data. PLOS ONE 2008, 3, e1408. [CrossRef] 
37. Eckert, S.; Hüsler, F.; Liniger, H.; Hodel, E. Trend analysis of MODIS NDVI time series for detecting land degradation and regeneration in Mongolia. J. Arid Environ. 2015, 113, 16-28. [CrossRef]

38. Ning, S.; Wang, J.; Jin, J.; Ishidaira, H. Assessment of the latest GPM-Era high-resolution satellite precipitation products by comparison with observation gauge data over the Chinese mainland. Water 2016, 8, 481. [CrossRef]

39. Shahabfar, A.; Eitzinger, J. Agricultural drought monitoring in semi-arid and arid areas using MODIS data. J. Agric. Sci. 2011, 149, 403-414. [CrossRef]

40. Xu, S.; Wu, C.; Wang, L.; Gonsamo, A.; Shen, Y.; Niu, Z. A new satellite-based monthly precipitation downscaling algorithm with non-stationary relationship between precipitation and land surface characteristics. Remote Sens. Environ. 2015, 162, 119-140. [CrossRef]

41. Brunsdon, C.; Fotheringham, A.S.; Charlton, M. Some notes on parametric significance tests for geographically weighted regression. J. Reg. Sci. 1999, 39, 497-524. [CrossRef]

42. Tu, J.; Xia, Z.G. Examining spatially varying relationships between land use and water quality using geographically weighted regression I: Model design and evaluation. Sci. Total Environ. 2008, 407, 358-378. [CrossRef] [PubMed]

43. Chen, Y.; Huang, J.; Sheng, S.; Mansaray, L.R.; Liu, Z.; Wu, H.; Wang, X. A new downscaling-integration framework for high-resolution monthly precipitation estimates: Combining rain gauge observations, satellite-derived precipitation data and geographical ancillary data. Remote Sens. Environ. 2018, 214, 154-172. [CrossRef]

44. Cheema, M.J.M.; Bastiaanssen, W.G.M. Local calibration of remotely sensed rainfall from the TRMM satellite for different periods and spatial scales in the Indus Basin. Int. J. Remote Sens. 2012, 33, 2603-2627. [CrossRef]

45. Laurent, L.; Audois, P.; Marie-Joseph, I.; Becker, M.; Seyler, F. Calibration of TRMM 3B42 with geographical differential analysis over North Amazonia. In Proceedings of the 2013 IEEE International Geoscience and Remote Sensing Symposium-IGARSS, Melbourne, VIC, Australia, 21-26 July 2013; pp. 2234-2237. [CrossRef]

46. Duan, Z.; Bastiaanssen, W.G.M. First results from Version 7 TRMM 3B43 precipitation product in combination with a new downscaling-calibration procedure. Remote Sens. Environ. 2013, 131, 1-13. [CrossRef]

47. Omranian, E.; Sharif, H.O. Evaluation of the global precipitation measurement (GPM) satellite rainfall products over the lower Colorado River Basin, Texas. JAWRA J. Am. Water Resour. Assoc. 2018, 54, 882-898. [CrossRef]

(C) 2019 by the authors. Licensee MDPI, Basel, Switzerland. This article is an open access article distributed under the terms and conditions of the Creative Commons Attribution (CC BY) license (http:/ / creativecommons.org/licenses/by/4.0/). 